\title{
Mitos culturais sobre o papel do professor e perspectivas da aprendizagem: um estudo de caso
}

\author{
Amanda Dinucci Almeida \\ PUC-Rio
}

\begin{abstract}
Resumo
O presente trabalho focaliza uma situação social híbrida. Trata-se da oficina de Língua Portuguesa do Centro Regional Integrado de Atendimento ao Adolescente (Criaa), um projeto de extensão vinculado ao Departamento de Psiquiatria e Saúde Mental do Instituto de Saúde da Comunidade da Universidade Federal Fluminense (UFF). Os objetivos deste estudo são produzir uma reflexão acerca das crenças aparentes da responsável pela oficina sobre o papel do professor e considerar as perspectivas da aprendizagem evidenciadas na descrição do seu trabalho. Essa reflexão se dá à luz destes construtos teóricos: os apontamentos de Britzman (1986) acerca das expectativas comuns de como os professores devem agir nas sociedades ocidentais; e a contraposição da noção de input a de affordance elaborada por van Lier (2002). A metodologia de pesquisa escolhida para tratamento dos dados se insere no âmbito da pesquisa qualitativa e interpretativa (DENZIN \& LINCOLN, 2006).
\end{abstract}

Palavras chave: professor, aprendizagem, mitos culturais.

\begin{abstract}
This paper focuses on a hybrid social situation: the workshop on Portuguese that takes place at Centro Regional Integrado de Atendimento ao Adolescente (Criaa), a project linked to the Department of Psychiatry and Mental Health at the Institute of Community Health of Universidade Federal Fluminense (UFF). It aims to provoke discussion and reflection on the beliefs of the person who is in charge of the workshop about the teacher's role and the perspectives on learning evident in the description of her work. This research is based on the following concepts: the notes of Britzman (1986) about the common expectations of how teachers should act in Western societies, and opposite notions of input and affordance (VAN LIER, 2002). The research methodology chosen for processing the data generated falls within the scope of qualitative and interpretive (DENZIN \& LINCOLN, 2006).
\end{abstract}

Keywords: teacher, learning, cultural myths. 


\section{INTRODUÇÃO}

A perspectiva científica dominante na sociedade ocidental leva não apenas pesquisadores, mas cada cidadão a pensar em polaridades cotidianamente. É verdade que esse pensamento permitiu grandes avanços, como os tecnológicos, por exemplo. No entanto, Palmer (1998, p. 62) salienta que o pensamento either-or, além de nos "confundir e trair frente aos problemas perenes da vida que estão além do alcance da lógica", também nos dá "uma noção fragmentada da realidade que destrói a totalidade e a beleza da vida" .

O fenômeno linguístico, por exemplo, apresenta uma dimensão cognitiva, mas sistemas e processos ecológicos também são essenciais para sua realização (VAN LIER, 1998). Assim, a definição, a estrutura e o uso linguísticos são intrinsecamente dialógicos, como observou Bahktin (1981). E uma análise que rejeita essa noção minimiza a complexidade desse fenômeno, tornando-o, portanto, menos interessante. Como Palmer (1998, p. 65) afirma brilhantemente: “os pólos de um paradoxo são como os pólos de uma bateria: junte-os, e eles gerarão a energia da vida; separe-os, e a corrente para de fluir".

O presente trabalho focaliza uma situação social híbrida buscando lançar sobre isso o olhar proposto por Palmer (idem). Trata-se da oficina de Língua Portuguesa do Centro Regional Integrado de Atendimento ao Adolescente (Criaa), um projeto de extensão vinculado ao Departamento de Psiquiatria e Saúde Mental do Instituto de Saúde da Comunidade da Universidade Federal Fluminense (UFF). Os objetivos deste trabalho são produzir uma reflexão, ainda que provisória, acerca das

${ }^{1}$ Foi utilizada uma tradução minha para as citações de Palmer (1998), Britzman (1986), Allwright (2003) e Stubbs (1983). 
crenças da oficineira ${ }^{2}$ sobre o papel do professor e considerar as perspectivas da aprendizagem evidenciadas na descrição do seu trabalho.

A instituição em questão se localiza em Niterói (RJ), e foi criada para atender adolescentes em situação de risco ou que já fazem uso de drogas lícitas e/ou ilícitas. É considerada um centro de atenção psicossocial - álcool e drogas (Caps-AD). Desde o início, esta instituição trabalha na perspectiva da redução de danos, uma estratégia que visa a diminuir os riscos causados aos consumidores de drogas sem interromper obrigatoriamente seu uso, numa busca pela inclusão social dos dependentes.

Sob essa orientação, além do atendimento médico, o Criaa-UFF promove oficinas de Ciências, História, Inglês, Português, Matemática, Música e Sociologia, além de duas oficinas de esporte. Na equipe de oficineiros, há jovens que ainda estão cursando a graduação e outros recém-formados em cursos de licenciatura. A oficineira de Português Clarice ${ }^{3}$ está em fase de conclusão do curso de Letras na Uerj, trabalha como professora em outras instituições e realiza essa atividade no Criaa-UFF uma vez por semana há dois anos.

O formato oficina, razoavelmente padronizado, somado ao contexto local da instituição selecionada, cria diferentes tipos de situação de interação - enquadres que se encaixam. Nessas laminações, é possível entrever a performance da oficineira Clarice como correspondente a de uma professora, dentro do enquadre aula, e como a de uma terapeuta, referente ao enquadre terapia, superposto ao outro.

No entanto, na entrevista que realizamos com a oficineira, ela busca construir seu papel profissional associando-o estritamente às atividades de uma terapeuta. Nesse estudo, analisaremos por que ela rejeita a atribuição do papel de professora, investigando os critérios nos quais se apoia a fim de perceber as crenças subjacentes.

\footnotetext{
${ }^{2}$ O termo "oficineiro" é empregado para designar o responsável pela realização das atividades de uma oficina.

${ }^{3}$ Um nome fictício foi usado para a preservação da identidade da entrevistada.
} 
Além disso, analisaremos a associação das suas ideias e práticas com perspectivas de aprendizagem.

Apresentamos, a seguir, as bases teóricas e metodológicas do trabalho. Seguese a isso a análise de dados e, por fim, as conclusões preliminares.

\section{FUNDAMENTOS TEÓRICOS E METODOLÓGICOS}

\section{Mitos culturais sobre o papel do professor}

É muito difícil que alguém não tenha uma noção do que faz um professor. Assim, quem realiza um curso de licenciatura traz para sua formação mais que um desejo de ensinar. Após anos de experiência em sala de aula, os futuros professores trazem para seus cursos suas biografias institucionais. Britzman (1986, p. 445) aponta expectativas comuns, muito específicas, de como os professores devem agir. Espera-se, por exemplo, que o professor "mantenha o controle da sala, faça as regras serem cumpridas e apresente um programa de estudos".

Numa análise mais ampla dos contextos pedagógicos, Britzman (ibidem) observa ainda que as escolas são hierarquicamente organizadas, o currículo é divido em compartimentos, além de o controle social ser uma dinâmica importante na vida em sala de aula. E destaca, embasada, por sua vez, em Apple (1982), que, enquanto essa descrição parece apenas caracterizar a organização ou a "estrutura da experiência", suas consequências são definitivamente políticas já que essa estrutura corresponde a interesses sociais, econômicos e ideológicos particulares da sociedade dominante.

Para que as práticas pedagógicas continuem correspondendo a esses interesses, Britzman (idem) analisa a forma como as histórias pessoais de cada professor interagem com mitos comuns da nossa cultura. Afinal, como salienta Liberali (2004, p. 92), “as visões e ações adotadas pelos professores são percebidas 
não como meras preferências pessoais, mas como resultantes das normas culturais e históricas que foram sendo absorvidas."

O que chamamos de "mitos culturais" são valores que, de acordo com Britzman (op. cit., p. 448), tendem a "racionalizar e legitimar a estrutura escolar existente assim como prover um semblante de ordem, controle, e certeza frente à incerteza do mundo do professor." $\mathrm{E}$, entre os mitos que ela aponta, dois são relevantes para esta pesquisa.

O primeiro é a crença de que tudo depende do professor (idem, p. 449). É dele a responsabilidade de apresentar o conteúdo, promover o aprendizado do aluno e manter o controle da sala. Isso leva a um isolamento ilustrado por Allwright (2003, p. 132) nessa afirmação: "Ensinar pode ser uma jornada solitária (como observado por alguém, o trabalho mais particular feito em público ou o mais público feito em particular)". Nesse contexto em que o professor se encontra isolado, se algo inesperado ocorre, é visto, geralmente, como ameaça à estabilidade do controle social e não uma oportunidade de aprendizagem.

Além de estar na posição de quem controla ou tentar controlar tudo, o professor é visto como o detentor do conhecimento. Isso se relaciona diretamente com o segundo mito que abordaremos, apontado por Britzman (idem, p. 450), o do professor como expert. É necessário contemplar a insegurança que isso causa não apenas nos futuros professores, mas naqueles que se dedicam cotidianamente ao ensino.

Não pode faltar ao professor nenhuma resposta como se, de fato, houvesse resposta para todas as perguntas e o conhecimento fosse um produto acabado e não em permanente construção. Como afirma Britzman (idem): “desse ponto de vista, os professores parecem ter aprendido tudo, e consequentemente não ter nada a aprender; o conhecimento aparece como algo finito e imutável".

\section{De input a affordances: perspectivas da aprendizagem}


A perspectiva ecológica da aprendizagem se opõe às premissas do pensamento científico padrão, que predomina na sociedade ocidental e teve impacto na formação dos mitos culturais existentes hoje. Essas premissas reduzem a aprendizagem ao seguinte processo: uma informação é recebida, processada no cérebro e incorporada em forma de estruturas mentais, resultando em conhecimento.

Nota-se que essa perspectiva de aprendizagem sustenta em sala de aula uma visão do aluno e do professor. A ideia que se reproduz é que a informação é transferida por um indivíduo que sabe mais - o professor - a outro que sabe menos o aluno. O professor é, portanto, aquele que fornece input a um recipiente passivo. Lançando outro olhar sobre a aprendizagem, a abordagem ecológica, não focaliza a quantidade de input disponível ou a quantidade de input necessária para a compreensão de determinada informação. $O$ foco se volta para as oportunidades de aprendizagem que a situação propicia. Assim, emergem outras noções do papel do professor e do aluno.

De acordo com van Lier (2002, p. 252), na teoria ecológica da percepção de Gibson, esse propiciamento/affordance não é uma propriedade do ator nem do objeto, mas uma relação entre os dois. Quem ensina e/ou pesquisa assumindo essa perspectiva substitui a noção de input pela de affordance, que se refere, no contexto pedagógico, à relação entre propriedades do ambiente e um aprendiz ativo (VAN LIER, 2002, p. 257).

Dessa forma, questiona-se a ideia de que as línguas e qualquer forma de conhecimento sejam exclusivamente produzidas e armazenadas no cérebro, e que a aprendizagem consistiria em formas variadas de introduzi-los lá. Há, portanto, uma ruptura com noções sustentadas durante muito tempo sobre a aprendizagem e uma ruptura consequente com os mitos culturais abordados por Britzman (1986).

\section{Metodologia da pesquisa}

Os dados para análise foram obtidos numa visita feita ao Criaa-UFF, quando obtivemos notas de campo, e num encontro posterior com a responsável pela oficina 
de Língua Portuguesa, quando foi gravada uma entrevista. Essa gravação em áudio, realizada em maio de 2012 , tem $11^{\prime}: 15^{\prime}$ '. A metodologia de pesquisa escolhida para tratamento dos dados, gerados a partir de orientação etnográfica, se insere no âmbito da pesquisa qualitativa e interpretativa (DENZIN \& LINCOLN, 2006).

\section{ANÁLISE DOS DADOS}

O segmento a seguir mostra o início da entrevista realizada com a oficineira de Língua Portuguesa, Clarice. Ela começa a descrição do seu trabalho na instituição em foco, e faz já um comentário avaliativo, comum em descrições como essa (LIBERALI, 2004).

\section{Segmento 1}

\begin{tabular}{|l|l|l|}
\hline T.4 & Clarice & $\begin{array}{l}\text { Eu sou professora de Português >quer dizer< oficineira de Português. } \\
\text { A gente dá oficinas terapêuticas, não é aula. A gente não tem } \\
\text { avaliação, nada disso. São:: estratégias de língua portuguesa, pra } \\
\text { chamar a atenção deles pra:::alguma coisa que não seja a droga. } \\
\text { Então, eu <utilizo a língua portuguesa> como:: meio para distraí-los. } \\
\text { É uma terapia. Através de português. (2.0) }{ }^{\circ} \text { Muito difícil de fazer. }{ }^{\text {o }}\end{array}$ \\
\hline
\end{tabular}

Primeiramente, Clarice atribui a si o papel de professora, fazendo depois um reparo para se qualificar como oficineira. A partir de então, busca construir seu papel profissional associando-o estritamente às atividades de uma terapeuta. Ela torna relevante, entre as atividades de papel (SARANGI, 2010; 2011) de um oficineiro, a distração dos pacientes. De acordo com a entrevistada, no seu encontro com eles, a língua portuguesa é apenas um "meio" para que isso seja desenvolvido, isto é, o aprendizado de conteúdos escolares não é a finalidade de suas práticas de trabalho cotidianas. 
Torna-se relevante ainda, em sua fala, a distinção entre o enquadre terapia e o enquadre aula. Sem que houvesse sido questionada a respeito disso, ela afirma como distintivo entre uma atividade de caráter terapêutico - como a oficina, segundo ela e uma atividade pedagógica, a avaliação. Percebe-se que Clarice inicia uma busca por justificar por que sua performance profissional no contexto do Criaa-UFF não corresponderia a de uma professora. Isso se desenvolve no segmento a seguir.

\section{Segmento 2}

\begin{tabular}{|l|l|l|}
\hline T.7 & Amanda & $\begin{array}{l}\text { Mas você acha que é diferente de ir pra escola? É diferente de uma } \\
\text { aula? }\end{array}$ \\
\hline T.8 & Clarice & $\begin{array}{l}\text { É. Completamente diferente. Porque não tem cobrança e:: também } \\
\text { não tem um planejamento de aula. Eu chego lá e: de acordo com o } \\
\text { que eles estão sentindo, como está a cabeça deles no momento, eu } \\
\text { tenho que inventar uma atividade que rela:xe, não que cobre nada. } \\
\text { Então, é bem diferente. E eu não sou a professora, eu sou alguém } \\
\text { que está interagindo, que vai participar também. É diferente, } \\
\text { completamente diferente. }\end{array}$ \\
\hline
\end{tabular}

A entrevistada destaca que, dentro do conjunto de atividades específicas do papel de professor, estaria a atividade de cobrar o aluno, pois ele, numa perspectiva racionalista e empirista, deve buscar evidências da aprendizagem (VAN LIER, 2002, p. 248), o que se relaciona à avaliação mencionada no segmento anterior. Mas, de acordo com ela, os oficineiros não realizam essa atividade, pois trabalham em “oficinas terapêuticas", que visam a "relaxar" o paciente.

Outra atividade destacada entre as específicas do professor é o planejamento de aulas. Clarice assinala que não é professora, pois não cabe a um oficineiro perceber oportunidades de aprendizagem. Ela não realiza a atividade de planejar as aulas da maneira que a cultura ocidental, na qual está inserida, afirma que é 
importante para a performance do papel de professor. Assim, não se entende como tal. Observa-se, nessas afirmações, que há expectativas muito específicas de como um professor deve agir, entre elas a apresentação de um programa de estudos, apontada por Britzman (1986, p. 445) como uma expectativa comum, sobre a qual a entrevistada fala utilizando o termo "planejamento".

Interessa-nos ainda no segmento 2 uma afirmação que põe em relevo outra expectativa: "eu não sou a professora, eu sou alguém que está interagindo, que vai participar também". Segundo Stubbs (1983, p. 17): "Há uma noção segundo a qual, na nossa cultura, ensinar é falar. Uma pesquisa em salas de aula tradicionais e relativamente formais mostra que, em média, os professores tendem a falar por aproximadamente 70 por cento do tempo da aula. (FLANDERS, 1970)". A entrevistada se alinha a essa concepção, pois nega a performance do papel de professor com base no papel discursivo que atribui a ele. Ao aluno corresponderia o papel discursivo de ouvinte e a ele o de falante.

Reverberam na fala de Clarice, assim, os valores da cultura ocidental que determinam as atividades atribuídas ao professor e geram expectativas quanto ao mesmo. Em relação às normas históricas e culturais absorvidas e reproduzidas em contextos pedagógicos, Stubbs (idem) afirma: "Muitas culturas têm conceitos bem diferentes de ensino e aprendizagem por meio da demonstração prática, participação supervisionada, observação, tentativa e erro".

Percebe-se que os conceitos de Clarice se desdobram sobre os mitos culturais apontados por Britzman (ibidem). A entrevistada constrói o papel do professor apoiada na dominação do piso interacional exercida pelo mesmo. Isso se articula ao mito que afirma que o professor é quem detém o conhecimento. Uma vez que o professor é o expert, caberiam a ele turnos muito mais longos, ao passo que os do aluno seriam apenas backchannels. Essas noções se associam a uma perspectiva de aprendizagem na qual está em foco o input que "um par mais competente" pode fornecer. 
De acordo com essa perspectiva, o aluno deveria receber as informações que o professor fornece, processá-las e armazená-las em forma de estruturais mentais. Para que o input necessário seja transmitido e isso ocorra de maneira adequada, o professor deve se planejar, e, para que se perceba se a transmissão ocorreu apropriadamente ou não, é necessário que se realizem avaliações. Por isso, Clarice pontua essas atividades de um professor, ou seja, planejar e cobrar.

Pautada no fato de que não as realiza, ela rejeita a qualificação de seu papel como o de uma professora. Sua argumentação serve para mostrar que suas práticas cotidianas de trabalho estariam associadas à performance de um papel profissional da área da saúde e não da educação. Num outro trecho, contudo, ela assume uma semelhança entre a performance de um oficineiro e a de um professor, revelando ainda outra crença quanto ao último.

\section{Segmento 3}

\begin{tabular}{|l|l|l|}
\hline T.31 & Amanda & Você acha que isso contribui pra você como professora? \\
\hline T.32 & Clarice & $\begin{array}{l}\text { Demais. Uma coisa que eu aprendi foi a controlar os alunos porque } \\
\text { lá... apesar de serem pacientes...são pacientes muito difíceis, são } \\
\text { meninos muito difíceis de lidar... porque eles não respeitam, eles } \\
\text { não tem essa... essa prática. Então, depois de- de lidar com isso, } \\
\text { saber controlar uma turma, chegar numa turma de } 6^{\circ} \text { ano, pra mim, } \\
\text { é brincadeira porque controlar as crianças é muito mais fácil. }\end{array}$ \\
\hline
\end{tabular}

Britzman (ibidem) ressalta que, além de apresentar um programa de estudos, espera-se que o professor mantenha o controle da sala e faça as regras serem cumpridas. Entende-se que "é trabalho do professor controlar grupos grandes de alunos para que a rotina da sala de aula possa acontecer.” (idem, p. 444). Essa concepção é evidenciada nesse segmento da entrevista, onde Clarice afirma que, 
controlando os pacientes, aprendeu a controlar os alunos e, assim, se aprimorou como professora.

Essa noção se relaciona ao mito apontado pela autora que afirma que tudo depende do professor. E, dentre tudo, destaca-se esse aspecto, geralmente chamado em contextos pedagógicos de "disciplina". Descombe (1982) salienta que os professores geralmente são avaliados por sua habilidade de orquestrar o controle da sala de aula. Por isso, Clarice afirma que sua experiência com pacientes "muito difíceis de lidar" contribuiu “demais" para sua carreira de professora.

Mas, apesar de a entrevistada apontar apenas o controle social como uma semelhança entre uma aula e uma oficina, percebe-se que, de acordo com a perspectiva ecológica, a oficineira pode ser considerada uma educadora também e não apenas uma terapeuta. O professor geralmente é visto como aquele que planeja um input, mas, seguindo a perspectiva ecológica, podemos também observá-lo como um profissional que é responsável por planejar a maior riqueza de oportunidades. Nos segmentos a seguir, em que a entrevistada cita exemplos de oficinas realizadas, observaremos como Clarice trabalha com oportunidades de aprendizagem ou affordances.

\section{Segmento 4}

\begin{tabular}{|l|l|l|}
\hline T.33 & Amanda & Tem alguma oficina que você lembre que tenha sido mais legal? \\
\hline T.34 & Clarice & $\begin{array}{l}\text { A oficina de ontem. Foi muito legal. Foi sobre cordel. Então em } \\
\text { vez de eu explicar o que seria literatura de cordel e tudo mais, eu } \\
\text { peguei vários textos de cordel e brinquei de a gente... ler os textos } \\
\text { em voz alta e algumas pessoas interpretarem. E eles gostaram } \\
\text { muito e, a partir dali, eu fui falando algumas características e eles } \\
\text { começaram a se interessar por literatura. Então, a próxima aula eu } \\
\text { já tenho como planejar porque eles pediram pra eu dar aula de } \\
\text { literatura de novo. }\end{array}$ \\
\hline
\end{tabular}




\section{Segmento 5}

\begin{tabular}{|l|l|l|}
\hline T.10 & Clarice & $\begin{array}{l}\text { Por exemplo, eu tenho uma paciente que é histérica. Ela num usa } \\
\text { drogas. A gente atende outras pessoas também. Que não tem nada a } \\
\text { ver com drogas ou álcool. Ela é histérica e ela quer passar no } \\
\text { vestibular. Então, se só tiver ela e eu tiver preparado uma atividade } \\
\text { terapêutica, eu posso mudar completamente a aula e ficar falando } \\
\text { com ela sobre o vestibular, sobre matéria de vestibular. Então é } \\
\text { imprevisível. }\end{array}$ \\
\hline
\end{tabular}

De início, é interessante notar, no segmento 4, que a entrevistada utiliza repetidas vezes o termo "aula" para tratar das oficinas. Além disso, percebe-se que o tema da oficina descrita corresponde a um conteúdo escolar. Uma vez que há oportunidade de aprender esse conteúdo, seja esse o objetivo principal ou não, entendemos que essa poderia ser considerada uma atividade pedagógica. Portanto, o enquadre aula estaria superposto ao enquadre terapia.

Cabe observar ainda que, embora Clarice afirme que não planeja as oficinas, à medida que conhece os pacientes, seus gostos e interesses, é possível pensar em atividades antes de realizá-las e, como ela apontou no segmento 4, eles expressam seus desejos. Segundo Britzman (1986), os alunos têm raras oportunidades de determinar o programa escolar. De fato, portanto, isso contraria uma expectativa comum na cultural ocidental quanto à dinâmica de uma aula.

Mas, no segmento 5, mais uma vez, a entrevistada utiliza esse vocábulo para caracterizar a oficina, o que demonstra a ambivalência dessa situação social. $O$ hibridismo de papéis fica evidente quando a oficineira diz que pode ter preparado uma atividade terapêutica, o que denota seu papel de terapeuta, e exercer uma atividade pedagógica voltada para os exames de vestibular, denotando um papel de 
professora. O manejo do footing se dá em virtude do objetivo do paciente que vai à oficina. Isso demonstra que a entrevistada trabalha com affordances, isto é, percebe e cria oportunidades, assim como qualquer professor poderia trabalhar também, caso tivesse essa liberdade concedida pela sua instituição.

\section{CONSIDERAÇÕES FINAIS}

$\mathrm{Na}$ análise dos dados, é possível notar que Clarice busca construir seu papel profissional no contexto do Criaa-UFF como o de uma terapeuta e justifica por que sua performance profissional não corresponderia a de uma professora na instituição embasada em critérios que apontam certas crenças. Os conceitos de Clarice se desdobram sobre dois mitos culturais apontados por Britzman (1986): tudo depende do professor e o professor detém o conhecimento.

Em suma, a entrevistada apresenta os seguintes construtos a respeito da performance desse profissional: é de sua responsabilidade planejar as aulas, ou seja, apresentar um programa de estudos, e avaliar a eficácia das práticas pedagógicas, buscando evidências da aprendizagem; e ele é quem domina o piso interacional, portanto, correspondem a ele os papel discursivos de falante e avaliador. Essas premissas associam a aprendizagem à noção de input.

Como nas oficinas a aprendizagem dos pacientes ocorre inserida numa outra dinâmica, a oficineira afirma que a atividade que eles realizam não seria uma aula. Afinal, no caso das oficinas, o paciente é quem ocupa o centro das atividades e é visto como uma pessoa responsável por sua própria vida e pela sua doença ou dependência química. Nesse contexto, a oficineira é uma facilitadora para que o paciente supra sua necessidade ou alcance seu objetivo, quer isso exija uma atuação terapêutica ou pedagógica.

Perceber o outro como um indivíduo único e capaz de tomar decisões, de ser responsável pela sua aprendizagem, enfim, de exercer autonomia é essencial na relação professor-aluno (ALWRIGHT \& HANKS, 2009). Portanto, considerando essa situação social como uma aula, além de uma atividade terapêutica, não só 
estaríamos diante de uma aula, mas de um excelente exemplo de como é possível tornar isso um empreendimento coletivo em que as pessoas cooperam umas com as outras, respeitando e desenvolvendo suas capacidades.

\section{REFERÊNCIAS}

Allwright, D. (2003). Exploratory Practice: Rethinking practitioner research in language teaching. In Ellis, R. (ed.) Language Teaching Research. London: Arnold, 7 (2), 113-141.

Allwright, D.; Hanks, J. (2009). The developing language learner: an introduction to exploratory practice. Basingstoke: Palgrave Macmillan.

Britzman, D. P. (1986). Cultural myths in the making of a teacher: biography and social structure in teacher education. Harvard Educational Review, 56 (4), 442-456.

Denzin, N. K.; Lincoln, Y. S. (orgs.). (2006) O Planejamento da Pesquisa Qualitativa: teorias e abordagens. ${ }^{\text {a }}$. ed. Porto Alegre: Artmed Bookman.

Liberali, F. C. (2004). As linguagens das reflexões. In Magalhães, M. (org.). A formação do professor como um profissional crítico: linguagem e reflexão. Campinas: Mercado das Letras, 87-117.

Palmer, P. J. (1998). The hidden wholeness. In The courage to teach: exploring the inner landscape of a teacher's life. San Francisco: Jossey-Bass Publishers, 61-113.

Sarangi, S. (2010). Reconfiguring self/identity/status/role: the case of professional role performance in healthcare encounters. In Archibald, J.; Garzone, G. (eds.). Actors, identities and roles in professional and academic settings: discursive perspectives. Berne: Peter Lang, 27-54.

(2011). Role hybridity in professional practice. In Sarangi, S. et al. (eds.). Genre(s) on the Move: Hybridisation and Discourse Change in Specialized Communication. Napoli: Edizioni Scientifiche Italiane (ESI).

Stubbs, M. (1983). Language, Schools and Classrooms. In Contemporary Sociology of the School.Suffolk: The Chaucer Press.

Tannen, D.; Wallat, C. (2002). Enquadres interativos e esquemas de conhecimento em interação: exemplos de um exame/consulta médica. In B.T. Ribeiro e P. Garcez (eds.), Sociolinguística Interacional. São Paulo: Loyola, 183-214 
Van Lier, L. (2002). From input to affordance: Social-interactive learning from an ecological perspective. In Lantolf, J. (Ed.) Sociocultural theory and second language learning. Oxford: Oxford University Press, 245-259.

\section{A AUTORA}

Amanda Dinucci Almeida possui licenciatura em Letras pela Universidade do Estado do Rio de Janeiro/UERJ (2011) e mestrado em Estudos de Linguagem pela Pontifícia Universidade do Rio de Janeiro/PUC-Rio (2014). Atualmente é aluna do Doutorado em Estudos de Linguagem na PUC-Rio.

E-mail: amandadinucci@ hotmail.com 